\title{
Inhibition of transendothelial migration and invasion of human breast cancer cells by preventing geranylgeranylation of Rho
}

\author{
TOSHIYUKI KUSAMA ${ }^{1,3,4}$, MUTSUKO MUKAI ${ }^{1}$, MASAHARU TATSUTA $^{2}$, \\ HIROYUKI NAKAMURA $^{1}$ and MASAHIRO INOUE ${ }^{1}$
}

\begin{abstract}
Departments of ${ }^{1}$ Tumor Biochemistry and ${ }^{2}$ Gastrointestinal Oncology, Osaka Medical Center for Cancer and Cardiovascular Diseases, 1-3-3 Nakamichi, Higashinari-ku, Osaka 537-8511; ${ }^{3}$ First Department of Surgery,

University of Yamanashi, School of Medicine, 1110 Tamaho, Nakakoma, Yamanashi 409-3898;

${ }^{4}$ Internal Oncology, Shinko Hospital, 1-4-47 Wakihama, Chuo-ku, Kobe 651-0072, Japan
\end{abstract}

Received January 18, 2006; Accepted March 16, 2006

\begin{abstract}
Rho family GTPases are frequently overexpressed in breast cancers, which regulate cancer cell migration and invasion. They require prenylation, a lipid post-translational modification, for full biological functions. We examined the effects of 3-Hydroxy-3-methylglutaryl-coenzyme A (HMG-CoA) reductase inhibitor (fluvastatin), a selective farnesyltransferase inhibitor (FTI-277) and a selective geranylgeranyltransferase type I inhibitor (GGTI-298) on in vitro invasive capacity of MDA-MB-231 human breast cancer cells into the endothelial cell monolayer in a transendothelial migration assay. Although, at a maximal dose of $5 \mu \mathrm{M}$, fluvastatin did not affect the integrity of endothelial cell monolayer, the transendothelial migration of MDA-MB-231 cells was inhibited potently by fluvastatin in a dose-dependent manner. The transendothelial migration of MDA-MB-231 cells was also inhibited potently by GGTI-298 in a dosedependent manner but weakly by FTI-277. The inhibitory effects of fluvastatin, GGTI-298 and FTI-277 on MDA-MB231 cell invasion were shown to correlate well with inhibition of the membrane localization of RhoA and RhoC, but not with Ras. These results suggest that geranylgeranylation step
\end{abstract}

Correspondence to: Dr Toshiyuki Kusama, Department of Tumor Biochemistry, Osaka Medical Center for Cancer and Cardiovascular Diseases, 1-3-3 Nakamichi, Higashinari-ku, Osaka 537-8511, Japan E-mail: kusama-to@ mc.pref.osaka.jp

Abbreviations: EGF, epidermal growth factor; IGF-II, insulin-like growth factor II; SDF-1ß, stromal cell-derived factor 1B; HMG-CoA, 3-hydroxy-3-methylglutaryl-coenzyme A; FTase, farnesyltransferase; GGTase-I, geranylgeranyltransferase type I; GGOL, all-transgeranylgeraniol; FOL, all-trans-farnesol

Key words: HMG-CoA reductase inhibitor, geranylgeranyltransferase, farnesyltransferase, Rho, transendotelial migration, invasion of RhoA and RhoC could be a good therapeutic target for the prevention of invasion and metastasis of breast cancer cells.

\section{Introduction}

Members of the Rho family of small GTPases play an essential role in a variety of cellular events related to cell adhesion to the extracellular matrix, cell morphology, cell motility and invasion, acting as molecular switches that cycle between GTP- and GDP-bound states (1). Rho GTPases, including RhoA and RhoC, are highly expressed in a variety of human cancers and, in some cases, Rho protein up-regulation and/or overexpression correlates with poor prognosis (2-5). A number of small GTPases depend on post-translational isoprenylation by specific transferases, farnesyltransferase (FTase) and geranylgeranyltransferase type I (GGTase-I), which in turn lead to their attachment to plasma membranes and subsequent biological function $(6,7)$.

The mevalonate pathway of cholesterol synthesis may have a relationship to the development of mammary tumors (8). HMG-CoA reductase activity is higher in mammary tumors than in normal mammary glands of rats (9), suggesting involvement of high HMG-CoA reductase activity and high levels of mevalonate-derived metabolites, such as isoprenoid compounds, in the biological aggressiveness of breast cancer. HMG-CoA reductase inhibitors in clinical use are reversible inhibitors that interfere with catalysis of the rate-limiting step in cholesterol biosynthesis. It has been reported that non-cholesterol lowering effects of $\mathrm{HMG}-\mathrm{CoA}$ reductase inhibitors could play a potentially beneficial role in patients with cancer $(10,11)$. HMG-CoA reductase inhibitors inhibit cancer cell invasion and metastasis (12-17), including that of breast cancer cells $(18,19)$.

It is well known that the integrity of the endothelium is a barrier against cancer cell invasion and interendothelial cell junctions are the principal routes of cancer cell invasion into the circulation and into secondary organs. Although it was demonstrated that the pretreatment of endothelial cell monolayer with lovastatin inhibits transendothelial migration of human colon cancer cells (20), no detailed data have been 
provided as yet on the exact mechanism(s) of the effects on the interaction of breast cancer cells with endothelial cell monolayer. In the present study, we examined the role of prenylation of small GTPases for in vitro transendothelial migration of human breast cancer cells using MDA-MB-231 highly invasive cancer cells and show the inhibition of in vitro invasive capacity of cancer cells by preventing the membrane localization of RhoA and RhoC in cancer cells.

\section{Materials and methods}

Materials. The following materials were purchased: fetal bovine serum (FBS) from Bio Whittaker (Walkersville, ML); RPMI-1640 from Life Technologies, Inc. (Grand Island, NY); GGTI-298 and FTI-277 from Calbiochem (La Jolla, CA); recombinant human EGF from AUSTRAL Biologicals (San Ramon, CA); recombinant human SDF-1B and recombinant human IGF-II from R\&D Systems, Inc. (Minneapolis, MN); growth factor reduced Matrigel from Becton-Dickinson Labware (Bedford, MA); transwell chambers from Costar (Cambridge, MA); mouse anti-RhoA monoclonal antibody and goat anti-RhoC polyclonal antibody from Santa Cruz Biotechnology (Santa Cruz, CA); anti-Ras monoclonal antibody from Transduction Laboratories (Lexington, KY); and all other chemicals and reagents from Sigma Chemical Co. (St. Louis, MO). GGTI-298 and FTI-277 were dissolved at $20 \mathrm{mM}$ in dimethyl sulfoxide (DMSO) and stored at $-80^{\circ} \mathrm{C}$. Fluvastatin was isolated from the marketed product, Tanabe Seiyaku Co. (Osaka, Japan). It was dissolved at $30 \mathrm{mM}$ in methanol and stored at $-20^{\circ} \mathrm{C}$.

Cells and cell cultures. The MDA-MB-231 human breast cancer cell line was obtained from the American Type Culture Collection (Rockvill, MD). MDA-MB-231 cells were grown in RPMI-1640 supplemented with $10 \%$ FBS, penicillin G (100 units/ml), and streptomycin $(100 \mu \mathrm{g} / \mathrm{ml})$. Calf pulmonary arterial endothelial (CPAE) cells were obtained from the Japanese Cancer Research Resources Bank (Osaka, Japan). CPAE cells were cultured in a medium containing a 1:1 ratio of Dulbecco's modified mimimal essential medium and Ham's nutrient mixture F-12 (DME/F-12) supplemented with $20 \%$ FBS. Cells were maintained at $37^{\circ} \mathrm{C}$ in a humidified atmosphere with $5 \%$ carbon dioxide.

Separation of cytosolic and membrane fractions. Separation of cytosolic and membrane fractions was performed as previously described (12). Subconfluent cells were washed with cold PBS and lysed by freeze-thawing in ice-cold lysis buffer containing $50 \mathrm{mM}$ HEPES ( $\mathrm{pH} 7.5$ ), $50 \mathrm{mM} \mathrm{NaCl}$, $2 \mathrm{mM}$ EDTA, $1 \mathrm{mM} \mathrm{MgCl}$, $10 \mathrm{mM}$ sodium fluoride, $1 \mathrm{mM}$ DTT, $10 \mu \mathrm{g} / \mathrm{ml}$ leupeptin, $10 \mu \mathrm{g} / \mathrm{ml}$ aprotinin, and $1 \mathrm{mM}$ phenylmethylsulfonyl fluoride and centrifuged at 100,000 x g for $30 \mathrm{~min}$ at $4^{\circ} \mathrm{C}$, and the supernatant was collected as the cytosolic fraction. Pellets were homogenized in the above lysis buffer containing $2 \%$ Triton $\mathrm{X}-114$ and centrifuged at $800 \mathrm{x} \mathrm{g}$ for $10 \mathrm{~min}$ at $4^{\circ} \mathrm{C}$. The supernatant was collected and is referred to here as the membrane fraction. The protein concentrations in the cytosolic fraction and the membrane fraction were measured using a DC protein assay kit (BioRad, Hercules, CA) and adjusted to the same concentration with the lysis buffer. These fractions were subjected to sodium dodecyl sulfate-polyacrylamide gel electrophoresis and transferred to Fine trap NT-31 membranes (Nihon Eido, Tokyo, Japan). After blocking, the membranes were incubated overnight at $4^{\circ} \mathrm{C}$ with the indicated primary antibodies and for $1 \mathrm{~h}$ with corresponding secondary horseradish peroxidaseconjugated antibodies. Membranes were washed three times in Tris-buffered saline containing 1\% Tween-20 for $5 \mathrm{~min}$ after each incubation step. Visualization was performed using an enhanced chemiluminescence kit (Amersham Pharmacia Biotech, Little Chalfont, Buckinghamshire, UK). The blot membranes were scanned and analyzed with NIH image software.

Transendothelial migration assay. The invasive ability of cancer cells into the endothelial cell monolayer was measured as the transcellular migration activity of the cancer cells by the method previously described $(21,22)$. CPAE cells were seeded at a density of $2 \times 10^{5}$ cells/dish on a $35-\mathrm{mm}$ plastic culture dish and grown for 4 days to a confluent monolayer. After the monolayer had been rinsed once with fresh culture medium, cancer cells were seeded on the monolayer at a density of $5 \times 10^{4}$ cells/dish. After coincubation for $16 \mathrm{~h}$ at $37^{\circ} \mathrm{C}$, non-adherent cells were removed by aspiration and the remaining cell layers were fixed in $10 \%$ formalin in PBS. The number of penetrated single cancer cells and cancer cell colonies (collectively called invasion foci) was counted under a phase-contrast microscope (Olympus, Tokyo, Japan) in 16 different visual fields $\left(1.13 \mathrm{~mm}^{2}\right.$ each). The activity of in vitro transendothelial invasion was expressed as the number of invasion foci $/ \mathrm{cm}^{2}$.

Matrigel invasion assay. Cell invasion through reconstituted basement membrane Matrigel was assayed by a previously reported method (12). Briefly, polycarbonate membranes of the upper compartment of Transwell culture chambers were coated with 5\% Matrigel. Cells were harvested and resuspended at $1 \times 10^{6} / \mathrm{ml}$ in serum-free medium with $0.1 \%$ fraction $\mathrm{V}$ bovine serum albumin (BSA). The cell suspension $(100 \mu 1)$ was placed in the upper compartment, and the lower compartment was immediately filled with $600 \mu 1$ of serum-free medium containing $0.1 \% \mathrm{BSA}$ and the indicated ligand. After $16 \mathrm{~h}$ of incubation, the membranes were stained with May-Grunwald and Giemsa's solution. Cells on the upper surface of the filter were carefully removed with a cotton swab, and the cells that had migrated through the membrane to the lower surface were counted in 9 different fields under a light microscope at magnification $\mathrm{x} 400$. Each experiment was performed in triplicate wells and repeated three times.

Wounding induced migration assay. CPAE cell migration was measured by an in vitro wound healing assay. Confluent CPAE cell monolayers were scraped with the tip of a micropipette. After washing with PBS, CPAE cells were incubated for $24 \mathrm{~h}$ in culture medium with or without fluvastatin. Monolayers were then fixed and the scraped area was evaluated.

Statistical analysis. The statistical significance of differences between groups was calculated by applying Student's 2-tailed t-test, and $\mathrm{P}<0.05$ was considered significant. 


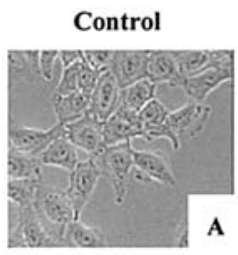

Fluvastatin

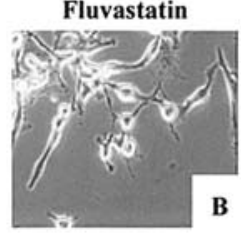

Fluvastatin + FOL

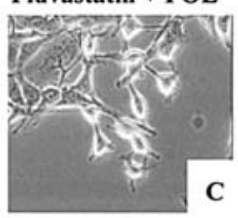

Fluvastatin + GGOL

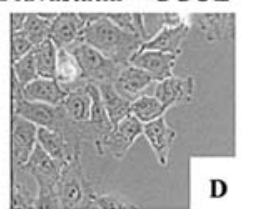

FTI-277

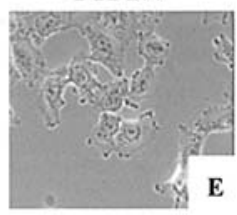

GGTI-298

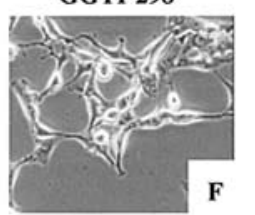

G

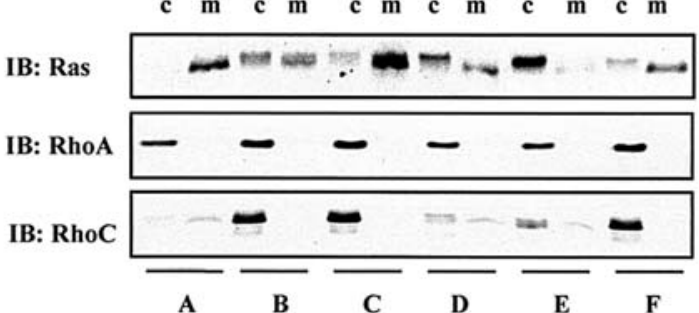

$\mathbf{H}$

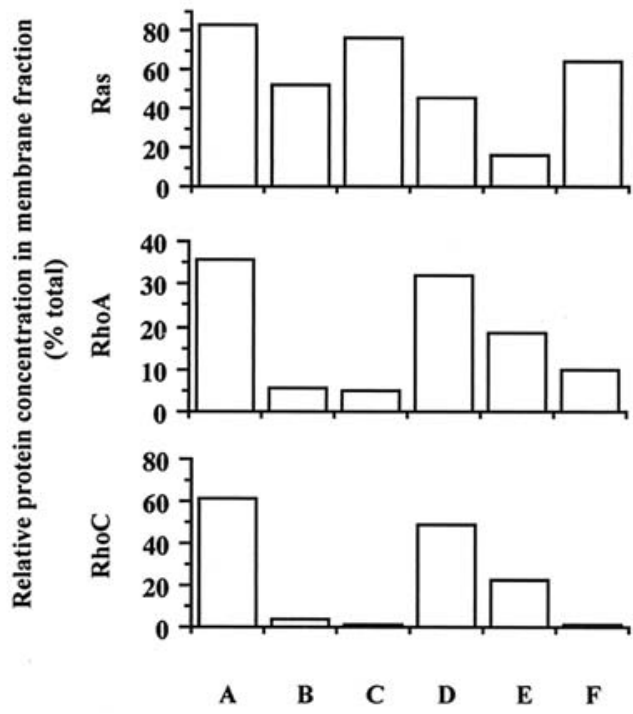

Figure 1. Effects of fluvastatin, FTI-277 and GGTI-298 on the morphologys of MDA-MB-231 cells (A-F). Cells were incubated for $24 \mathrm{~h}$ in the culture medium in the absence or presence of indicated additions and observed by phase-contrast microscopy. (A) Untreated MDA-MB-231 cells; (B) MDAMB-231 cells treated with $1 \mu \mathrm{M}$ fluvastatin only; (C) MDA-MB-231 cells treated with fluvastatin and $1 \mu \mathrm{M}$ FOL; (D) MDA-MB-231 cells treated with fluvastatin and $1 \mu \mathrm{M}$ GGOL; (E) treated with $5 \mu \mathrm{M}$ FTI-277; (F) treated with $5 \mu \mathrm{M}$ GGTI-298. (G) Western blot analysis of the effects of fluvastatin, FTI-277 and GGTI-298 on the translocation of small G proteins. Cells were incubated for $24 \mathrm{~h}$ in the culture medium in the absence or presence of indicated additions, as described for A-F. Proteins were extracted and separated into cytosolic (c) and membrane (m) fractions, and then Ras, RhoA and RhoC proteins were detected by immunoblotting as described in Materials and methods. (H) Relative protein concentration of Ras, RhoA and $\mathrm{RhoC}$ in the membrane fraction (percentage of total). Columns represent the means of two independent experiments.

\section{Results}

Effects of geranylgeranylated RhoA and RhoC on MDA$M B-231$ cell morphology. Previously, we have reported the involvement of geranylgeranylation of RhoA in actin filament reorganization and in vitro invasion of cancer cells (12-15). In order to examine the role of prenylation of small GTPases for in vitro transendothelial migration of human breast cancer cells, we first studied the effects of HMG-CoA reductase inhibitor (fluvastatin), a selective FTase inhibitor (FTI-277) and a selective GGTase-I inhibitor (GGTI-298) on the morphology of MDA-MB-231 cells. Untreated MDA-MB-231 cells were flat and well spread (Fig. 1A) but exposure of cells to $1 \mu \mathrm{M}$ fluvastatin resulted in cell retraction from the substratum and rounding up (Fig. 1B). Although cells treated with fluvastatin in the presence of all-trans-farnesol (FOL) remained rounding (Fig. 1C), cells treated with fluvastatin in the presence of alltrans-geranylgeraniol (GGOL) were well spread like the control cells (Fig. 1D). Cells treated with $5 \mu \mathrm{M}$ FTI-277 were spread like control cells (Fig. 1E), whereas treatment cells with $5 \mu \mathrm{M}$ GGTI-298 resulted in cell retraction from the substratum and rounding up, like fluvastatin-treated cells (Fig. 1F).

The cytosolic and membranous protein pools of Ras, RhoA and RhoC were examined by Western blot analysis. As shown in Fig. $1 \mathrm{G}$ and $\mathrm{H}$, the treatment of MDA-MB-231 cells with $1 \mu \mathrm{M}$ fluvastatin for $24 \mathrm{~h}$ caused Ras, RhoA and RhoC to accumulate in the cytosolic fraction and decrease in the membrane fraction. The addition of GGOL, but not FOL, to fluvastatin-treated cells prevented the accumulation of RhoA and RhoC in the cytosolic fraction. In contrast, the addition of FOL, but not GGOL, to fluvastatin-treated cells caused Ras to remain in the membrane fraction. The treatment of cells for $24 \mathrm{~h}$ with FTI-277 caused Ras to accumulate in the cytosolic fraction and decrease in the membrane fraction, whereas GGTI-298 did not affect the translocation of Ras. In contrast, GGTI-298 caused RhoA and RhoC to accumulate in the cytosolic fraction and decrease in the membrane fraction, whereas the effect of FTI-277 on the accumulation of RhoA and RhoC in the cytosolic fraction was weak.

Effects of fluvastatin, FTI-277 and GGTI-298 on the transendothelial migration of MDA-MB-231 cells. The presence of $5 \mu \mathrm{M}$ fluvastatin did not affect the morphology of CPAE cell monolayer during the 24-h incubation period, as evaluated by phase-contrast microscopy (Fig. 2A and B). The effect of fluvastatin on the in vitro ability of MDA-MB-231 cells to invade the endothelial cell monolayer was measured by the transendothelial migration assay $(21,22)$. Typical shapes of the MDA-MB-231 cells penetrating the CPAE cell monolayer are shown in Fig. 2C (arrow-heads). Although MDAMB-231 cells could adhere to the cell-cell junction between adjacent CPAE cells, the transendothelial migration of MDAMB-231 cells was inhibited by the addition of fluvastatin in a dose-dependent manner (Fig. 2D and E). The inhibitory effect of fluvastatin on the transendothelial migration of MDA-MB-231 cells was reversed by the addition of GGOL but not FOL (Fig. 2E). Although the presence of $10 \mu \mathrm{M}$ FTI-277 or GGTI-298 did not affect the morphology of the CPAE cell monolayer during the 24-h incubation period (data not shown), the transendothelial migration of MDA-MB-231 cells was inhibited potently by GGTI-298 in a dose-dependent manner but weakly by FTI-277 (Fig. 2F). 

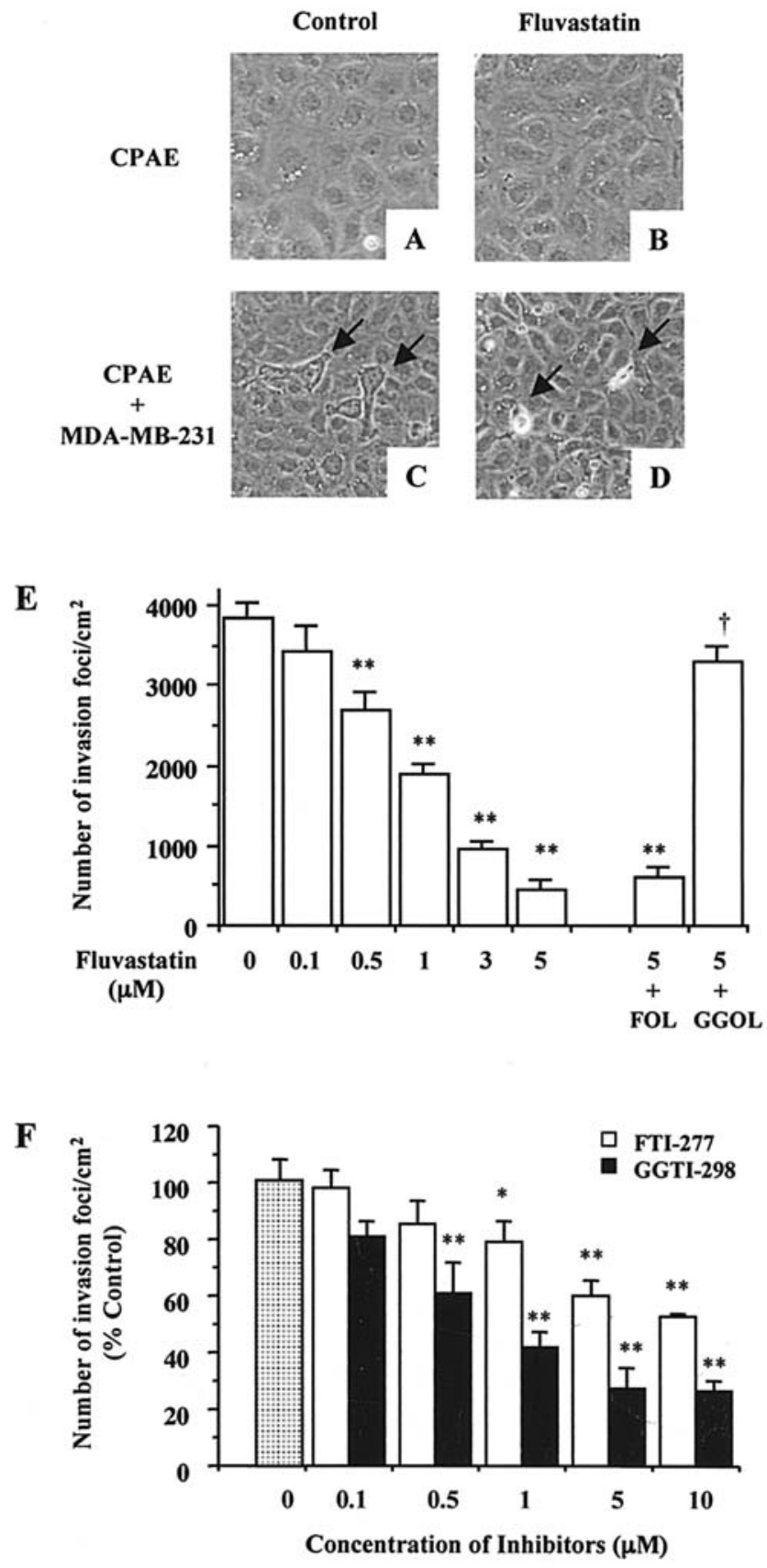

Figure 2. Effect of fluvastatin on the morphology of the CPAE cell monolayer (A and B). CPAE cell monolayers were incubated for $24 \mathrm{~h}$ in the culture medium in the absence (A) or presence (B) of $5 \mu \mathrm{M}$ fluvastatin and observed by phase-contrast microscopy. Effect of fluvastatin on the transendothelial migration of MDA-MB-231 cells (C and D). MDA-MB-231 cells were resuspended in DME/F-12 containing 20\% FBS in the absence (C) or presence (D) of $1 \mu \mathrm{M}$ fluvastatin and then seeded on CPAE cell monolayer. (E) Dose-dependence study of the effect of fluvastatin and the effects of FOL and GGOL on fluvastatin-treated cells. Cells were resuspended in DME/F-12 containing 20\% FBS with the indicated concentration of fluvastatin in the absence or presence of $1 \mu \mathrm{M}$ FOL or $1 \mu \mathrm{M} \mathrm{GGOL}$. (F) Effects of FTI-277 and GGTI-298 on the transendothelial migration of MDA-MB-231 cells. Cells were resuspended in the medium with the indicated concentration of FTI-277 ( $\square$ ) or GGTI-298 (घ). Migration across the CPAE cell monolayer was assessed after $16 \mathrm{~h}$. Data are expressed as means $\pm \mathrm{SE}$ of three separate experiments. ${ }^{*} \mathrm{P}<0.05$; ${ }^{* *} \mathrm{P}<0.01$ vs. control. ${ }^{\dagger} \mathrm{P}<0.01$ vs. fluvastatin-treated cells.

Effects of fluvastatin, FTI-277 and GGTI-298 on MDA-MB-231 cell invasion. MDA-MB-231 cells showed invasion through the Matrigel-coated membranes of a Transwell culture chamber in response to EGF, IGF-II and SDF-1ß. The increased invasion of MDA-MB-231 cells was inhibited by the addition of fluvastatin (Fig. 3A). Although GGOL and FOL did not induce the invasion of control cells without EGF stimulation, the inhibitory effect of fluvastatin on EGF-induced MDA-MB-231 cell invasion was reversed by the addition of GGOL but not FOL (Fig. 3B). GGOL also blocked the inhibitory effect of fluvastatin on MDA-MB-231 cell invasion induced by SDF-Iß and IGF-II (data not shown). EGF-induced invasion of MDA-MB-231 cells was inhibited potently by GGTI-298 in a dose-dependent manner but weakly by FTI-277 (Fig. 3B). The inhibitory effect of FTI-277 on EGF-induced MDA-MB-231 cell invasion was reversed by the addition of GGOL, but the inhibitory effect of GGTI-298 on EGF-induced MDA-MB-231 cell invasion was not reversed by the addition of GGOL (Fig. 3C).

Effect of fluvastatin on endothelial cell migration. Endothelial cell migration was measured by an in vitro wound healing assay. As shown in Fig. 4, the migration of CPAE cells was not affected during the 24-h incubation period with fluvastatin at doses of $1-3 \mu \mathrm{M}$ but a high concentration of fluvastatin (5-10 $\mu \mathrm{M})$ significantly inhibited the migration of CPAE cells.

\section{Discussion}

Overexpression of RhoA significantly correlated with poorer prognosis of patients with breast cancer (3). Furthermore, overexpression of RhoC was identified in $>90 \%$ of inflammatory breast cancers (4) and RhoC was defined as a mammary oncogene involved in conferring the metastatic phenotype (5). Recently, it was reported that transfection with anti-RhoA or anti-RhoC siRNA induced down-regulation of RhoA or RhoC, which in turn inhibited the proliferation and invasion of breast cancer cells (23). These data suggest the possibility that Rho proteins could be a good therapeutic target for the prevention of invasion and metastasis of breast cancer cells.

Our previous works demonstrated that HMG-CoA reductase inhibitors have the potential to reduce in vitro cancer cell invasion and experimental liver metastasis by preventing the membrane localization and activation of RhoA (12-15). In the present study, we show that fluvastatin and GGTI-298 inhibit in vitro transendothelial migration of MDA-MB-231 cells by preventing the membrane localization of RhoA and RhoC in cancer cells without affecting the integrity of the endothelial cell monolayer. This conclusion is confirmed by the following observations: a) the treatment of MDA-MB-231 cells with $1 \mu \mathrm{M}$ fluvastatin caused cell rounding (Fig. 1B) and inhibited the transendothelial migration of MDA-MB-231 cells (Fig. 2D and E) whereas, at a maximal dose of $5 \mu \mathrm{M}$, fluvastatin did not affect the morphology of the CPAE cell monolayer (Fig. 2B); b) the inhibitory effects of fluvastatin on cell morphology, the membrane localization of RhoA and RhoC, and transendothelial migration of MDA-MB-231 cells were reversed by the addition of GGOL but not by the addition of FOL (Figs. 1 and 2E); c) treatment of MDA-MB231 cells with FTI-277 or GGTI-298 prevented the membrane localization of RhoA and RhoC (Fig. 1G and H), and inhibited the transendothelial migration of MDA-MB-231 cells (Fig. 2F), 

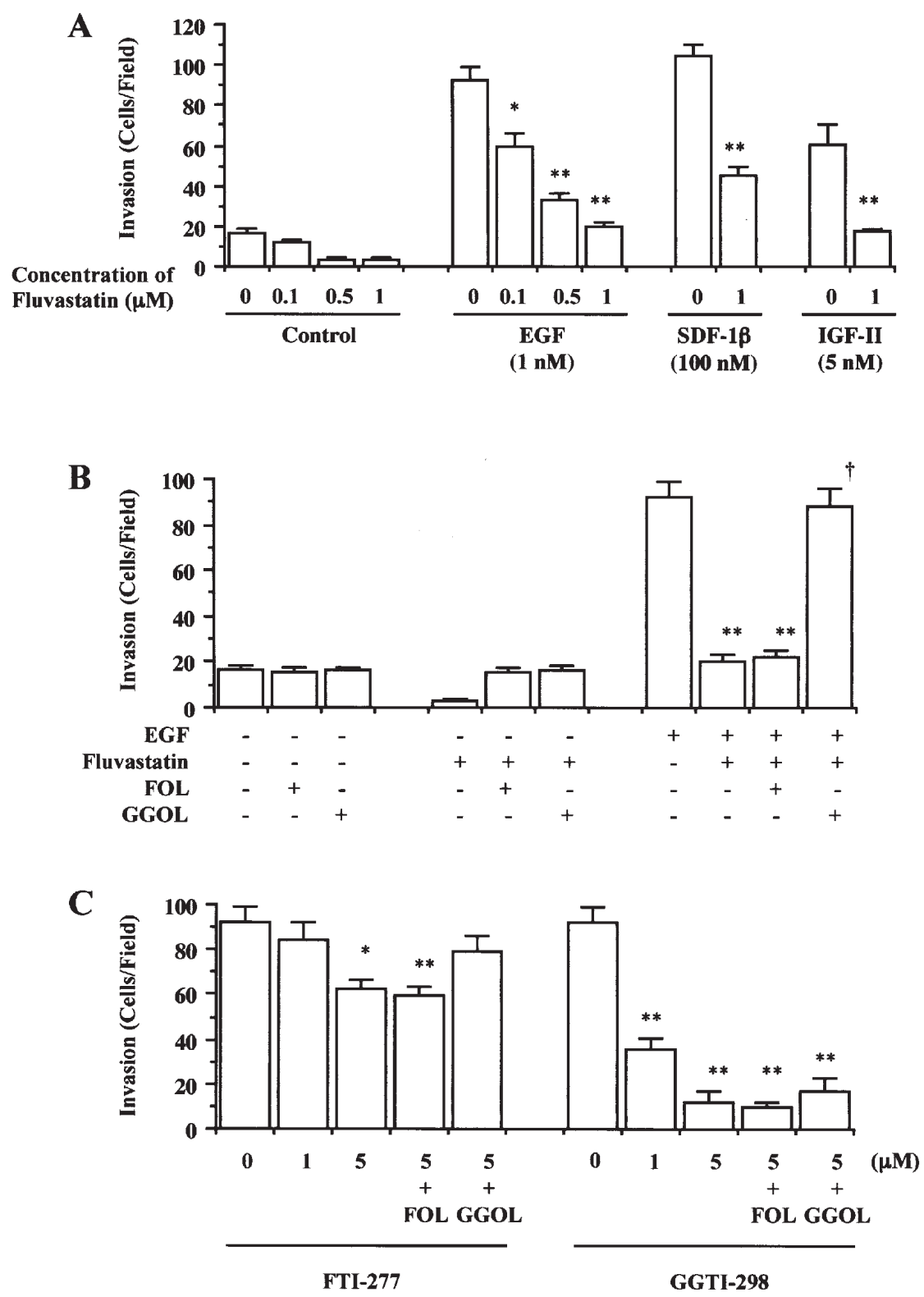

Figure 3. (A) Effects of fluvastatin on in vitro invasion of MDA-MB-231 cells. Cells were resuspended in serum-free medium containing 0.1\% BSA with the indicated concentration of fluvastatin. The cells (1x105/well) were added to the upper compartment, and the lower compartment was immediately filled with the same medium containing $1 \mathrm{nM}$ EGF, $100 \mathrm{nM}$ IGF-1ß, or $5 \mathrm{nM}$ IGF-II. (B) The effects of FOL and GGOL on in vitro invasion of MDA-MB-231 cells. Cells were resuspended in serum-free medium containing $0.1 \%$ BSA with or without $1 \mu \mathrm{M}$ fluvastatin in the absence or presence of $1 \mu \mathrm{M}$ FOL or $1 \mu \mathrm{M}$ GGOL. (C) Effects of FTI-277 and GGTI-298 on EGF-induced invasion of MDA-MB-231 cells. Cells were resuspended in serum-free medium containing $0.1 \%$ BSA with indicated concentrations of FTI-277 or GGTI-298 in the absence or presence of $1 \mu \mathrm{M}$ FOL or $1 \mu \mathrm{M}$ GGOL. In vitro invasion was assessed after $16 \mathrm{~h}$. Data are expressed as means $\pm \mathrm{SE}$ of three separate experiments in triplicate wells. ${ }^{*} \mathrm{P}<0.05 ;{ }^{* *} \mathrm{P}<0.01$ vs. control with ligand stimulation. ${ }^{\dagger} \mathrm{P}<0.01$ vs. fluvastatin-treated cells with EGF stimulation.

but the effects of FTI-277 were weak. Recently, we demonstrated that FTI-277 and GGTI-298 inhibit the in vitro invasion of human colon cancer cells and FTI-277 has an inhibitory effect on cancer cell invasion only at doses that affect the membrane localization of RhoA (15).

Breast cancer is often associated with the overexpression of a variety of mitogenic growth factors and their receptors, which have been found to play a leading role in the progression of breast cancer $(24,25)$. We previously showed that fluvastatin attenuates the EGF-induced in vitro invasion of human pancreatic cancer cells without inhibiting the tyrosine phosphorylation of EGF receptor and c-erb-B-2 (12). In the present study, fluvastatin and GGTI-298 inhibited the invasion of
MDA-MB-231 cells in response to not only EGF but also IGF-II and SDF-1B (Fig. 3), indicating that the inhibitory effects of fluvastatin and GGTI-298 were not specific to EGF-induced cancer cell invasion. Although GGOL alone did not induce the invasiveness of control cells without EGF stimulation (Fig. 3B), under conditions where tyrosine kinase receptors were active but $\mathrm{HMG}-\mathrm{CoA}$ reductase was not (treatment with EGF and fluvastatin), GGOL enhanced the in vitro invasion of MDA-MB-231 cells (Fig. 3B). Under conditions where tyrosine kinase receptors were active but GGTase-I was not (treatment with EGF and GGTI-298), GGOL did not induce the invasiveness of MDA-MB-231 cells (Fig. 3C). These results suggest that both activation 
A

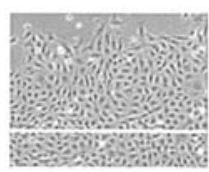

0

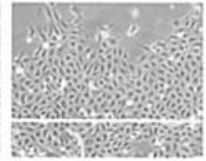

1

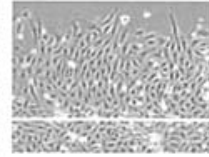

3

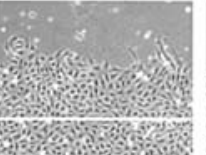

5

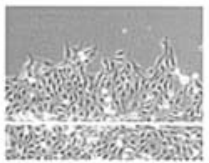

10

Concentration of Fluvastatin $(\mu \mathrm{M})$

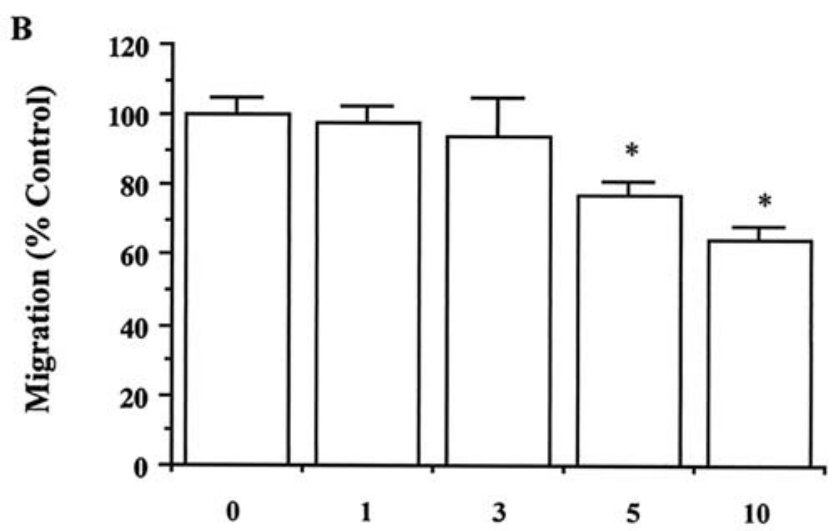

Concentration of Fluvastatin $(\mu \mathrm{M})$

Figure 4. (A) Effect of fluvastatin on the migration of CPAE cells. The scraped CPAE cell monolayers were incubated for $24 \mathrm{~h}$ in DME/F-12 containing $20 \%$ FBS in the absence or presence of an indicated concentration of fluvastatin and photographed by phase-contrast microscopy. (B) Results are expressed as the percentage of cell migration compared with that of untreated controls. Data points and columns represent the means \pm SE of at least 6 determinations from three separate experiments. ${ }^{*} \mathrm{P}<0.05$ vs. control.

of tyrosine kinase receptors and GGTase-I are necessary for cancer cell invasion and the geranylgeranylation step of Rho proteins could be a good therapeutic target for the prevention of invasion and metastasis of breast cancer cells overexpressing mitogenic growth factors and their receptors.

We previously demonstrated that endothelial cell retraction, which results in the breakdown of the barrier function of the endothelial cell monolayer, is an important factor in transendothelial migration of cancer cells (22). Endothelial cell retraction is mediated by activation of $\operatorname{RhoA}(26,27)$. Further investigation is necessary to make clear the possibility that HMG-CoA reductase inhibitors prevent transendothelial migration of cancer cells in part by inhibition of Rho-mediated endothelial cell retraction.

Denoyelle et al demonstrated that HMG-CoA reductase inhibitor cerivastatin inhibits both proliferation and invasiveness of MDA-MB-231 cells. The proliferation of MDA-MB-231 cells was significantly inhibited at low concentrations (5-10 ng/ $\mathrm{ml}$ ) but the invasion of MDA-MB-231 cells was significantly inhibited at high concentrations $(25-50 \mathrm{ng} / \mathrm{ml})(19)$, which was higher than the peak plasma concentration of cerivastatin $(5.4-13.8 \mathrm{ng} / \mathrm{ml})(28)$. In the present study, a significant inhibitory effect of fluvastatin on transendothelial migration of MDA-MB-231 cells was observed at a concentration of $0.5 \mu \mathrm{M}$, and half-maximum inhibition was estimated to occur at about $1 \mu \mathrm{M}$ (Fig. 2E). The inhibitory concentration of fluvastatin was comparable to the plasma concentration of fluvastatin $(0.1-1.5 \mu \mathrm{M})$ detected in clinical trials $(29,30)$ and it did not affect the morphology of CPAE cell monolayer and migration of CPAE cells (Figs. 2B and 4). These data suggest that fluvastatin has the potential to prevent breast cancer cell invasion at concentrations that might be relatively non-toxic to normal cells in comparison to most presently used anticancer agents.

\section{Acknowledgements}

This study was supported by a Grant-in-Aid for the SecondTerm Comprehensive 10-Year Strategy for Cancer Control from the Ministry of Health and Welfare of Japan.

\section{References}

1. Hall A: Rho GTPases and the actin cytoskeleton. Science 279: 509-514, 1998.

2 Suwa H, Ohshio G, Imamura T, Watanabe G, Arii S, Imamura M, Narumiya S, Hiai $\mathrm{H}$ and Fukumoto M: Overexpression of the rhoC gene correlates with progression of ductal adenocarcinoma of the pancreas. Br J Cancer 77: 147-152, 1998

3. Fritz G, Just I and Kaina B: Rho GTPases are over-expressed in human tumors. Int J Cancer 81: 682-687, 1999.

4. Van Golen KL, Davies S, Wu ZF, Wang Y, Bucana CD, Root H, Chandrasekharappa S, Strawderman M, Ethier SP and Merajver SD: A novel putative low-affinity insulin-like growth factor-binding protein, LIBC (lost in inflammatory breast cancer), and RhoC GTPase correlate with the inflammatory breast cancer phenotype. Clin Cancer Res 5: 2511-2519, 1999.

5. Kleer CG, van Golen KL, Zhang Y, Wu ZF, Rubin MA and Merajver SD: Characterization of RhoC expression in benign and malignant breast disease: a potential new marker for small breast carcinomas with metastatic ability. Am J Pathol 160: 579-584, 2002.

6. Elson CE, Peffley DM, Hentosh P and Mo H: Isoprenoid-mediated inhibition of mevalonate synthesis: potential application to cancer. Proc Soc Exp Biol Med 221: 294-311, 1999. 
7. Zhang FL and Casey PJ: Protein prenylation: molecular mechanisms and functional consequences. Annu Rev Biochem 65: 241-269, 1996.

8. El-Sohemy A and Archer MC: Regulation of mevalonate synthesis in rat mammary glands by dietary $n-3$ and $n-6$ polyunsaturated fatty acids. Cancer Res 57: 3685-3687, 1997.

9. El-Sohemy A and Archer MC: Inhibition of N-methyl-Nnitrosourea- and 7,12-dimethylbenz $[a]$ anthracene-induced rat mammary tumorigenesis by dietary cholesterol is independent of Ha-Ras mutations. Carcinogenesis 21: 827-831, 2000.

10. Kawata S, Yamasaki E, Nagase T, Inui Y, Ito N, Matsuda Y, Inada M, Tamura S, Noda S, Imai Y and Matsuzawa Y: Effect of pravastatin on survival in patients with advanced hepatocellular carcinoma. A randomized controlled trial. Br J Cancer 84: 886-891, 2001.

11. Poynter JN, Gruber SB, Higgins PD, Almog R, Bonner JD, Rennert HS, Low M, Greenson JK and Rennert G: Statins and the risk of colorectal cancer. N Engl J Med 352: 2184-2192, 2005.

12. Kusama T, Mukai M, Iwasaki T, Tatsuta M, Matsumoto $\mathrm{Y}$, Akedo $\mathrm{H}$ and Nakamura $\mathrm{H}$ : Inhibition of epidermal growth factor-induced RhoA translocation and invasion of human pancreatic cancer cells by 3-hydroxy-3-methylglutaryl-coenzyme A reductase inhibitors. Cancer Res 61: 4885-4891, 2001.

13. Kusama T, Mukai M, Iwasaki T, Tatsuta M, Matsumoto $\mathrm{Y}$, Akedo $\mathrm{H}$, Inoue $\mathrm{M}$ and Nakamura H: 3-hydroxy-3-methylglutarylcoenzyme A reductase inhibitors reduce human pancreatic cancer cell invasion and metastasis. Gastroenterology 122: 308-317, 2002.

14. Kusama T, Mukai M, Ayaki M, Imamura F, Tatsuta M, Matsumoto $\mathrm{Y}$, Nakamura $\mathrm{H}$ and Inoue $\mathrm{M}$ : Inhibition of lysophosphatidic acid-induced RhoA activation and tumor cell invasion by 3-hydroxy-3-methylglutaryl-coenzyme A reductase inhibitors. Int J Oncol 23: 1173-1178, 2003.

15. Kusama T, Mukai M, Tatsuta M, Matsumoto Y, Nakamura H and Inoue M: Selective inhibition of cancer cell invasion by a geranylgeranyltransferase-I inhibitor. Clin Exp Metastasis 20: 561-567, 2003.

16. Collisson E, Kleer C, Wu M, De A, Gambhir S, Merajver S and Kolodney M: Atorvastatin prevents RhoC isoprenylation, invasion, and metastasis in human melanoma cells. Mol Cancer Ther 2: 941-948, 2003.

17. Horiguchi A, Sumitomo M, Asakuma J, Asano T, Asano T and Hayakawa M: 3-hydroxy-3-methylglutaryl-coenzyme a reductase inhibitor, fluvastatin, as a novel agent for prophylaxis of renal cancer metastasis. Clin Cancer Res 10: 8648-8655, 2004.

18. Alonso DF, Farina HG, Skilton G, Gabri MR, De Lorenzo MS and Gomez DE: Reduction of mouse mammary tumor formation and metastasis by lovastatin, an inhibitor of the mevalonate pathway of cholesterol synthesis. Breast Cancer Res Treat 50: 83-93, 1998.
19. Denoyelle C, Vasse M, Korner M, Mishal Z, Ganne F, Vannier JP, Soria J and Soria C: Cerivastatin, an inhibitor of HMG-CoA reductase, inhibits the signaling pathways involved in the invasiveness and metastatic properties of highly invasive breast cancer cell lines: an in vitro study. Carcinogenesis 22: 1139-1148, 2001.

20. Mehta N, Hordies J, Sykes D, Doerr RJ and Cohen SA: Low density lipoproteins and lovastatin modulate the organ-specific transendothelial migration of primary and metastatic human colon adenocarcinoma cell lines in vitro. Clin Exp Metastasis 16: 587-594, 1998.

21. Akedo H, Shinkai K, Mukai M, Mori Y, Tateishi R, Tanaka K, Yamamoto R and Morishita T: Interaction of rat ascites hepatoma cells with cultured mesothelial cell layers: a model for tumor invasion. Cancer Res 46: 2416-2422, 1986.

22. Kusama T, Nakamori S, Ohigashi H, Mukai M, Shinkai K, Ishikawa O, Imaoka S, Matsumoto Y and Akedo $\mathrm{H}$ : Enhancement of in vitro tumor-cell transcellular migration by tumor-cellsecreted endothelial-cell-retraction factor. Int J Cancer 63: 112-118, 1995.

23. Pille JY, Denoyelle C, Varet J, Bertrand JR, Soria J, Opolon P, $\mathrm{Lu} \mathrm{H}$, Pritchard LL, Vannier JP, Malvy C, Soria C and Li H: Anti-RhoA and anti-RhoC siRNAs inhibit the proliferation and invasiveness of MDA-MB-231 breast cancer cells in vitro and in vivo. Mol Ther 11: 267-274, 2005.

24. Kim H and Muller WJ: The role of the epidermal growth factor receptor family in mammary tumorigenesis and metastasis. Exp Cell Res 253: 78-87, 1999.

25. Muller A, Homey B, Soto H, Ge N, Catron D, Buchanan ME, McClanahan T, Murphy E, Yuan W, Wagner SN, Barrera JL, Mohar A, Verastegui E and Zlotnik A: Involvement of chemokine receptors in breast cancer metastasis. Nature 410: 50-56, 2001.

26. Wojciak-Stothard B, Entwistle A, Garg R and Ridley AJ: Regulation of TNF- $\alpha$-induced reorganization of the actin cytoskeleton and cell-cell junctions by Rho, Rac, and Cdc42 in human endothelial cells. J Cell Physiol 176: 150-165, 1998.

27. Carbajal JM and Schaeffer RC Jr: RhoA inactivation enhances endothelial barrier function. Am J Physiol 277 (Cell Physiol 46): C955-C964, 1999.

28. Stein E, Isaacsohn J, Stoltz R, Mazzu A, Liu MC, Lane C and Heller AH: Pharmacodynamics, safety, tolerability, and pharmacokinetics of the 0.8 -mg dose of cerivastatin in patients with primary hypercholesterolemia. Am J Cardiol 83: 1433-1436, 1999.

29. Tse FLS, Jaffe JM and Troendle A: Pharmacokinetics of fluvastatin after single and multiple doses in normal volunteers. J Clin Pharmacol 32: 630-638, 1992.

30. Desager J-P and Horsmans Y: Clinical pharmacokinetics of 3-hydroxy-3-methylglutaryl coenzyme A reductase inhibitors. Clin Pharmacokinet 31: 348-371, 1996. 